\title{
Growth and properties of InAs $\mathrm{Sb}_{1-x}, \mathrm{Al}_{y} \mathrm{Ga}_{1-y} \mathrm{Sb}$, and $\operatorname{InAs}_{x} \mathrm{Sb}_{1-x} / \mathrm{Al}_{y} \mathrm{Ga}_{1-y} \mathrm{Sb}$ heterostructures
}

\author{
J.H. Kim, D. Yang, Y.-C. Chen and P. Bhattacharya \\ Solid State Electronics Laboratory, Department of Electrical Engineering and Computer Science, The University of Michigan, Ann Arbor, \\ Michigan 48109-2122, USA
}

A series of undoped $\mathrm{InSb}$ and $\mathrm{InAs}_{x} \mathrm{Sb}_{1-x}$ layers were grown using tetramer $\mathrm{Sb}_{4}$ and $\mathrm{As}_{4}$ sources on (100)-oriented semi-insulating GaAs and InP substrates with different growth parameters. Very high electron mobilities $(70,000$ and 110,000 $\mathrm{cm}^{2} / \mathrm{V} \cdot \mathrm{s}$ in InSb at 300 and $77 \mathrm{~K}$, respectively) and n-type conductivity are obtained for all alloy compositions. The flux ratio $P_{\mathrm{Sb}} / P_{\text {In }}$ played a crucial role in determining the surface morphology and the mobility of InSb films. Barrier heights of $\mathrm{Al} / \mathrm{p}-\mathrm{Al}_{y} \mathrm{Ga}_{1-\gamma} \mathrm{Sb}$ Schottky diodes are measured and are $0.4 \mathrm{eV}$. A $300 \AA$ Si-doped In $\mathrm{As}_{0.8} \mathrm{Sb}_{0.2}$ channel region sandwiched between undoped $\mathrm{Al}_{0.4} \mathrm{Ga}_{0.6} \mathrm{Sb}$ buffer and gate barrier regions has $\mu=1000 \mathrm{~cm}^{2} / \mathrm{V} \cdot \mathrm{s}$ and $n_{\mathrm{s}}=5.4 \times 10^{12} \mathrm{~cm}^{-2}$ at $300 \mathrm{~K}$. $1 \mu \mathrm{m}$ gate FETs made with this heterostructure have shown a maximum extrinsic $g_{\mathrm{m}}=160 \mathrm{mS} / \mathrm{mm}$ and $f_{\mathrm{T}}=5 \mathrm{GHz}$ at $300 \mathrm{~K}$.

\section{Introduction}

The Sb-containing alloys, and their heterostructures are becoming increasingly important for long-wavelength optoelectronic and cryogenic electronic device applications. In particular, the InAs $\mathrm{Sb}_{1-x}$ alloys produce the lowest bandgap in the family of III-V compounds. They are therefore suitable for detectors and sources operating at wavelengths in the 3-5 $\mu \mathrm{m}$ and 8-12 $\mu \mathrm{m}$ windows where the atmospheric absorption goes to a minimum [1-3]. However, in the development of materials and heterostructures for application to high speed and high frequency microelectronics, the antimony-bearing compounds have lagged behind. There are several reasons for this. Lack of suitable substrates and their large lattice mismatch to GaAs and InP is one. The existence of large miscibility gaps precludes the growth of high quality materials at lower temperatures by equilibrium and non-equilibrium techniques. On the other hand, because of their low bandgaps, the transport properties are expected to improve considerably at low temperatures and therefore these materials and devices would be important for cryogenic applications. However, recent epitaxial materials grown by molecular beam epitaxy (MBE) exhibit type conversion and degradation of the transport properties as the measurement temperature is lowered from $300 \mathrm{~K}$ [4-6].

InAs, InSb, and their binary alloys have favorable transport properties compared to GaAs or InP. As mentioned above, they have higher lowfield mobility. In addition, the $\Gamma-\mathrm{L}$ and $\Gamma-\mathrm{X}$ intervalley separations are about $1 \mathrm{eV}$ or larger, leading to negligible intervalley scattering and higher peak velocities. This will potentially improve the performance of submicron devices also. Therefore, if some of the problems mentioned earlier can be alleviated, one stands to gain from the superior materials characteristics.

In this paper, we report the growth and transport properties of InAs $\mathrm{Sb}_{1-x}$ heteroepitaxial layers, and the characteristics of $\mathrm{Al}_{y} \mathrm{Ga}_{1-y} \mathrm{Sb} / \mathrm{Al}$ Schottky diodes. We have also investigated In $\mathrm{As}_{x} \mathrm{Sb}_{1-x} / \mathrm{Al}_{y} \mathrm{Ga}_{1-y} \mathrm{Sb}$ heterostructures grown by MBE on GaAs and InP substrates for the realization of field effect transistors (FETs). Finally, we report the structure of $\operatorname{InAs} s_{x} \mathrm{Sb}_{1-x} / \mathrm{Al}_{y}$ $\mathrm{Ga}_{1-y} \mathrm{Sb}$ heterostructure field effect transistor (HFET) and its performances. The DC and high frequency performance of $1 \mu \mathrm{m}$ gate FETs made 
with InAsSb/AlGaSb heterostructures are described.

2. The growth and transport properties of $\operatorname{InAs}_{x} \mathbf{S b}_{1-x}$

Heteroepitaxial InAs $\mathrm{Sb}_{1-x}$ layers $(0 \leq x \leq 1)$ were grown on Fe-doped (100 InP substrates and semi-insulating GaAs (100) substrates in a Riber 2300P MBE system. Elemental arsenic and antimony were used as the group $\mathrm{V}$ sources, producing predominantly $\mathrm{As}_{4}$ and $\mathrm{Sb}_{4}$ species. After oxygen desorption under $\mathrm{As}_{4}$ overpressure $\left(1.5 \times 10^{5}\right.$ Torr), the growth of InAsSb was initiated as substrate temperature ranging from $350-500^{\circ} \mathrm{C}$, as measured by an infrared pyrometer. The growth rate varied in the range $0.8-1.0 \mu \mathrm{m} / \mathrm{h}$ and the flux ratio $J_{\mathrm{Sb}_{4}} / J_{\text {In }}$ was varied in the range of 0.3 to 4.0. The thickness of these directly grown layers varied in the range of $1.0-14.0 \mu \mathrm{m}$. In-situ examination of the crystalline nature of growth was done by reflection high energy electron diffraction (RHEED) measurements with $10 \mathrm{keV}$ electron beams along the (110) azimuth. The observed spotty nature of the RHEED pattern at the initiation of growth indicates a three dimensional growth mode resulting from the large lattice mismatch. After growth of a few hundred angströms, the spots change to streaks with a $(1 \times 3)$ reconstruction, indicating continuous coverage and smoothening of the growth front. Our observations were essentially same as those in previous reports [7].

We have grown InSb films ( $1 \mu \mathrm{m}$ thick) on (100) InP substrates with different partial pressure ratios $P_{\mathrm{Sb}_{4}} / P_{\mathrm{In}}$. The measured room-temperature Hall mobilities of $1 \mu \mathrm{m}$ InSb films grown on InP with different partial pressure ratios are shown in fig. 1 as a function of the partial pressure ratio. All the samples are n-type and the highest electron mobility can be observed in the sample with $P_{\mathrm{Sb}_{4}} / P_{\mathrm{In}}$ ratio of 6 and a corresponding beam flux ratio $J_{\mathrm{Sb}_{4}} / J_{\mathrm{In}}$ of 2 . The above observations suggest that the flux ratio, $J_{\mathrm{Sb}_{4}} / J_{\text {In }}$, plays a crucial role in determining the surface morphology and the electron mobility in the heteroepitaxial InSb films due to the high sticking coefficient of $\mathrm{Sb}_{4}$ molecules at

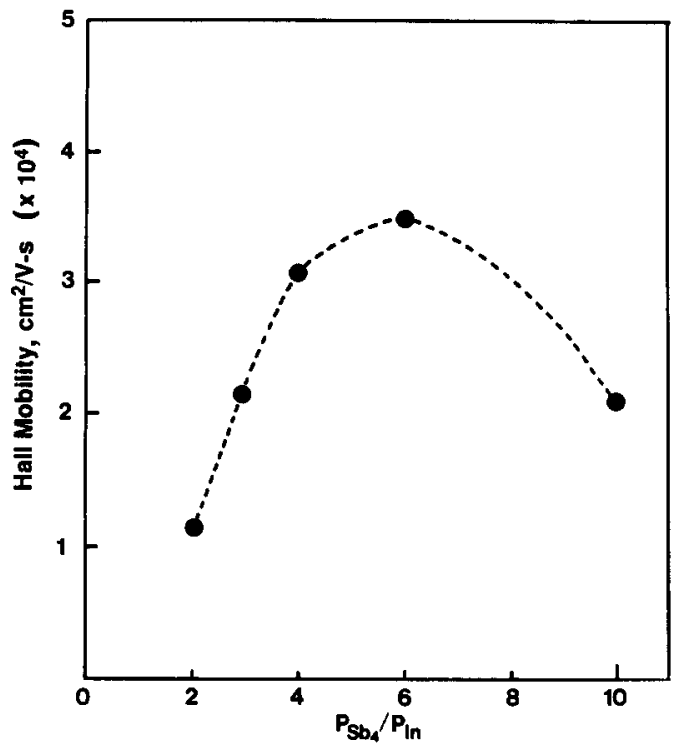

Fig. 1. Variation of measured Hall mobilities with $p_{\mathrm{Sb}_{4}} / P_{\mathrm{In}}$ in $1 \mu \mathrm{m} \mathrm{InSb}$ films grown on InP at $380^{\circ} \mathrm{C}$ and $1 \mu \mathrm{m} / \mathrm{h}$. The dashed line joins the data points.

the growth temperature used. Similar results were obtained in the InSb films grown on (100) GaAs substrates. The measured mobilities of $\operatorname{InAs}{ }_{x} \mathrm{Sb}_{1-x}$ with different composition ratios are shown in fig. 2. All samples are n-type. The mobility of InSb is $70,000 \mathrm{~cm}^{2} / \mathrm{V} \cdot \mathrm{s}$ at room temperature and 110,000

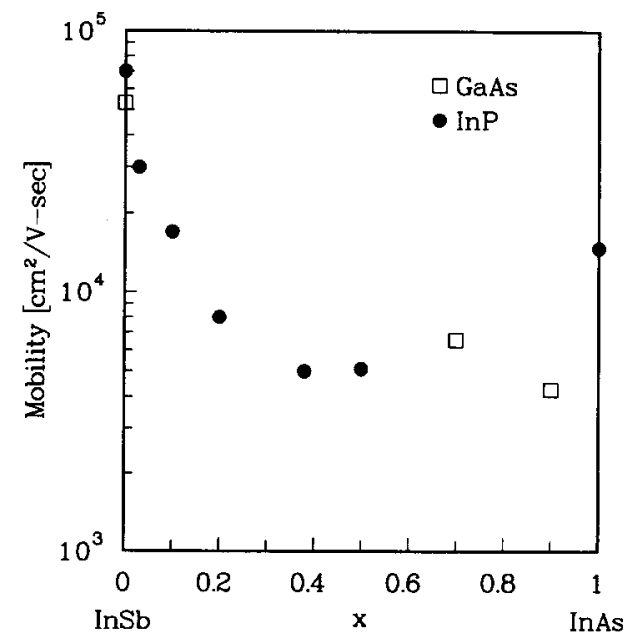

Fig. 2. Variation of measured room-temperature electron mobility with alloy compositions in InAs $\mathrm{Sb}_{1-x}$ films grown on GaAs and InP. 

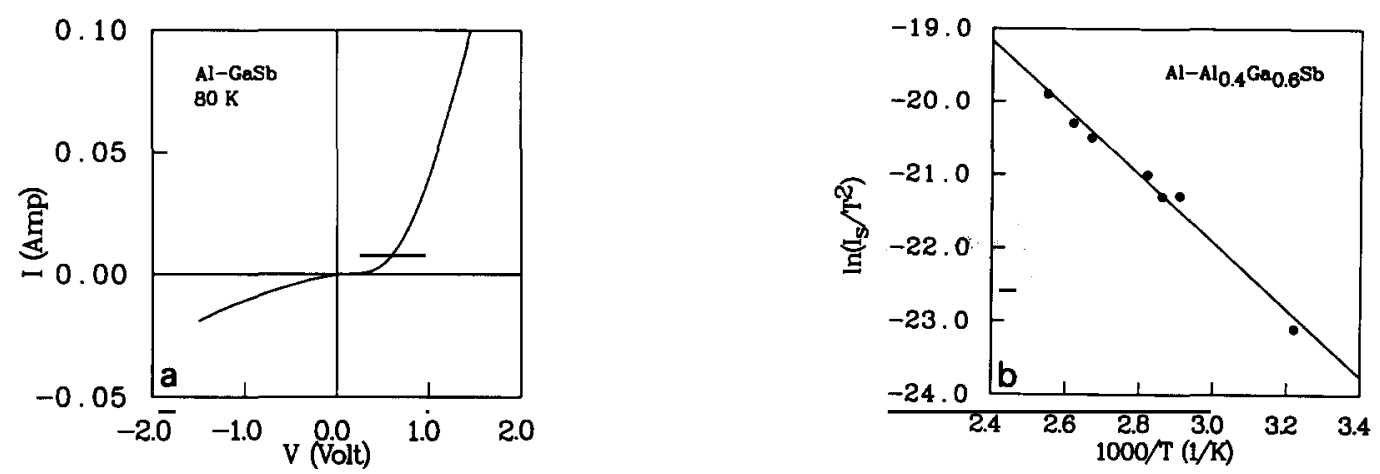

Fig. 3. (a) $I-V$ characteristics at $80 \mathrm{~K}$ of Al/GaSb diodes and (b) $\ln \left(J_{\mathrm{s}} / T^{2}\right)$ versus $10^{3} / T$ plot of $\mathrm{Al} / \mathrm{Al}_{0.4} \mathrm{Ga}_{0.6} \mathrm{Sb}_{\text {diode. }}$.

$\mathrm{cm}^{2} / \mathrm{V} \cdot \mathrm{s}$ at $77 \mathrm{~K}$, and the mobility of InAs on InP is $15,000 \mathrm{~cm}^{2} / \mathrm{V} \cdot \mathrm{s}$ at room temperature. The mobility rapidly drops with alloying, probably due to a combination of increased lattice mismatch and clustering effects. However, the mobility values compare very favorably with InAs $\mathrm{Sb}_{1-x}$ films grown by liquid phase epitaxy on InSb substrates. This also indicates that clustering effects rather than dislocation effects are responsible for the degradation in mobility.

\section{The growth and schottky diode characteristics of} $\mathrm{Al}_{y} \mathrm{Ga}_{1-y} \mathrm{Sb}$ epitaxial layers

An important parameter in the design and fabrication of FETs are the barrier height and leakage current of the Schottky gate contact. Since in our heterostructures, the Schottky diode is fabricated on an AlGaSb layer, we have examined the properties of $\mathrm{Al} / \mathrm{AlGaSb}$ Schottky diodes. A 1 $\mu \mathrm{m}$ layer of $\mathrm{AlGaSb}$ Be-doped p-type $5 \times 10^{16}$ $\mathrm{cm}^{-3}$ was grown on $\mathrm{P}^{+}-\mathrm{GaSb}$ substrates. $500 \mu \mathrm{m}$ diameter Al Schottky diodes were made on the layers by electron beam evaporation through a shadow mask. Forward and reverse-bias currentvoltage measurements were made on the diodes as a function of temperature in the range $80-400 \mathrm{~K}$. The $I-V$ characteristics of a GaSb diode at $80 \mathrm{~K}$ are shown in fig. 3a. The reverse saturation current is $8.83 \mu \mathrm{A}$ and the breakdown voltage is $3 \mathrm{~V}$. Fig. 3b shows the $\ln \left(J_{\mathrm{s}} / T^{2}\right)$ versus $10^{3} / T$ plot for an $\mathrm{Al}_{0.4} \mathrm{Ga}_{0.6} \mathrm{Sb}$ diode in accordance with the Richardson equation. The barrier heights obtained from the analysis of these data are 0.37 and $0.4 \mathrm{eV}$ for $\mathrm{GaSb}$ and $\mathrm{Al}_{0.4} \mathrm{Ga}_{0.6} \mathrm{Sb}$, respectively. Mead and Spitzer $[8,9]$ and Sadiq and Joullie [10] have reported barrier heights of 0.55 and $0.7 \mathrm{eV}$ for $\mathrm{Au} / \mathrm{p}$-type AlSb Schottky diodes. Mead and Spitzer cleaved the samples in vacuum before depositing the $\mathrm{Au}$ layer. Assuming an increase of barrier height with bandgap, our results are in fair agreement with the data of Mead and Spitzer. These are first reported data on barrier height of MBE grown AlGaSb.

\section{The structures and the performance of} $\operatorname{InAs}_{0.8} \mathrm{Sb}_{0.2} / \mathrm{Al}_{0.4} \mathrm{Ga}_{0.6} \mathrm{Sb}$ HFET

For an FET it is important to realize a thin channel with good transport properties. We used InAsSb as a channel and AlGaSb as a barrier material. The schematics of the doped-channel heterostructure FET grown on semi-insulating GaAs is shown in fig. 4. The sheet electron concentration and mobility in the $300 \AA$ Si-doped In $\mathrm{As}_{0.8} \mathrm{Sb}_{0.2}$ channel at $300 \mathrm{~K}$ are $5.4 \times 10^{12} \mathrm{~cm}^{-2}$

\begin{tabular}{ll}
\hline $100 A$ & $n=2 \times 10^{18} \mathrm{~cm}^{-3} \ln A s$ \\
\hline $400 A$ & Undoped AlGaSb Barrier \\
\hline $300 A \quad n=2 \times 10^{18} \mathrm{~cm}^{-3} \ln A s S b$ Channel \\
\hline $7 \mu \mathrm{m} \quad$ Undoped AlGaSb Buffer \\
\hline
\end{tabular}

Fig. 4. Schematic of InAsSb/AlGaSb heterostructure FET grown by MBE on GaAs. 

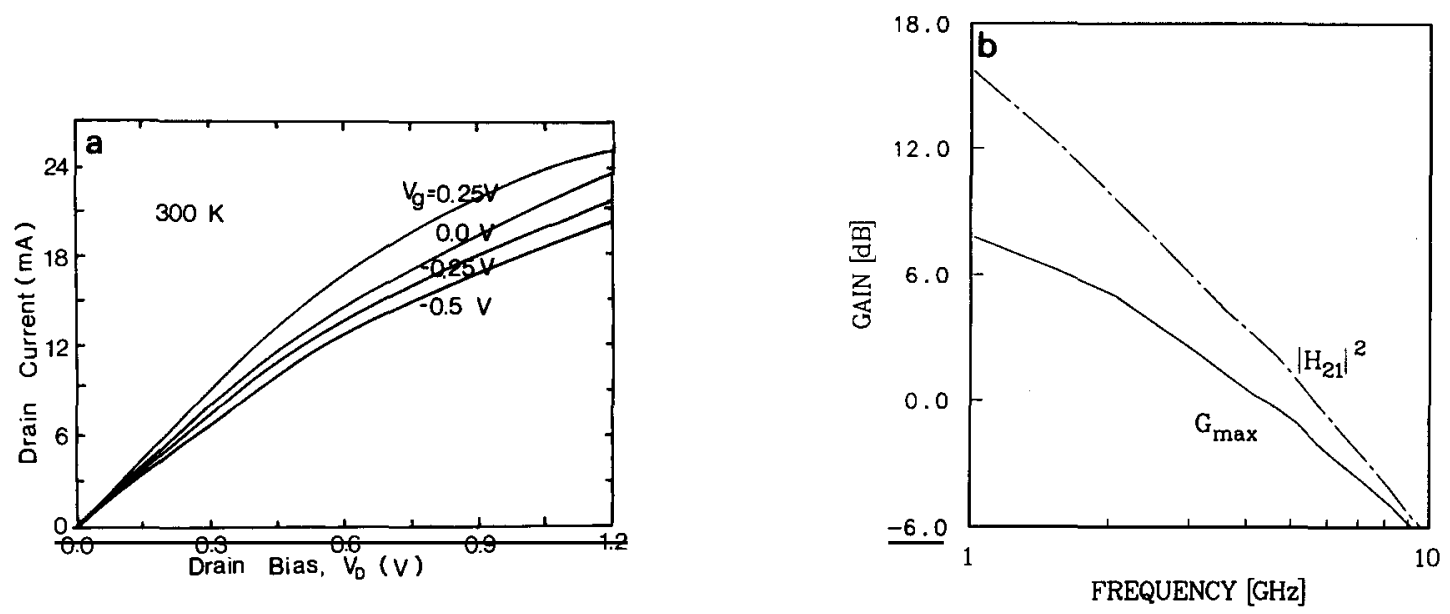

Fig. 5. Measured (a) DC and (b) microwave performance at room temperature for InAsSb/AlGaSb heterostructure FET.

and $1000 \mathrm{~cm}^{2} / \mathrm{V} \cdot \mathrm{s}$, respectively. Recently, FETs with an undoped channel using the InAs/AlGaSb (or AlSb) heterostructure were reported by Tuttle and Kroemer [11] and Luo et al. [12].

$1 \mu \times 50 \mu \mathrm{m}$ gate FETs with a source-drain spacing of $3.5 \mu \mathrm{m}$ were made by standard photolithography techniques. The source and drain contacts were made with electron beam evaporated $\mathrm{Au} / \mathrm{Ge} / \mathrm{Ni}$ and subsequent alloying. $\mathrm{Al}$ gate contacts were formed by electron beam evaporation. Measured room-temperature current-voltage characteristics of the devices are shown in fig. 5a. The devices cannot be pinched off due to a large parallel conduction. The maximum measured transconductance at $300 \mathrm{~K}$ is $160 \mathrm{mS} / \mathrm{mm}$. The $S$-parameter measurements were made on the devices with a CASCADE probe station and a 8510 automatic network analyzer. The measured current gain is shown in fig. $5 \mathrm{~b}$. The unity gain cut-off frequency $f_{\mathrm{T}}$ is found to be $5 \mathrm{GHz}$.

\section{Conclusion}

We have grown high quality $\operatorname{InAs}_{x} \mathrm{Sb}_{1-x}(0 \leq x$ $\leq 1$ ) directly on InP and GaAs substrates by molecular beam epitaxy. The undoped crystals are all n-type at $300 \mathrm{~K}$ and at low temperature. The surface morphology and electrical transport properties are strongly dependent on the $J_{\mathrm{Sb}_{4}} / J_{\text {In }}$ flux ratio and substrate temperature. The highest mo- bilities in InSb $\left(10 \mu \mathrm{m}\right.$ thick) are $70,000 \mathrm{~cm}^{2} / \mathrm{V} \cdot \mathrm{s}$ and $300 \mathrm{~K}$ and $110,000 \mathrm{~cm}^{2} / \mathrm{V} \cdot \mathrm{s}$ at $77 \mathrm{~K}$, and lower values are measured in the alloys.

We have also investigated the suitability of $\mathrm{Al}_{y} \mathrm{Ga}_{1-y} \mathrm{Sb}$ as a buffer and gate barrier layer in heterostructure FETs. Al Schottky contacts were evaporated on these p-type films and temperaturedependent current-voltage measurements were made. Barrier heights of 0.37 and $0.39 \mathrm{eV}$ are measured in $\mathrm{GaSb}$ and $\mathrm{Al}_{0.4} \mathrm{Ga}_{0.6} \mathrm{Sb}$, respectively.

We have made a $300 \AA$ Si-doped $\operatorname{InAs}_{0.8} \mathrm{Sb}_{0.2}$ channel structure, sandwiched between undoped $\mathrm{Al}_{0.4} \mathrm{Ga}_{0.6} \mathrm{Sb}$ buffer and gate barrier region. It shows $\mu=1000 \mathrm{~cm}^{2} / \mathrm{V} \cdot \mathrm{s}$ and $n_{\mathrm{s}}=5.4 \times 10^{12}$ $\mathrm{cm}^{-2}$ at $300 \mathrm{~K} .1 \mu \mathrm{m}$ gate FETs made with this heterostructure, showed a maximum extrinsic $g_{\mathrm{m}}$ $=160 \mathrm{mS} / \mathrm{mm}$ and $f_{\mathrm{T}}=5 \mathrm{GHz}$ at $300 \mathrm{~K}$.

\section{Acknowledgements}

The work is supported by NASA-Lewis under grant NAG-3-988 and the ARO (URI Program) under Contract DAALO03-87-K0007.

\section{References}

[1] G.C. Osbourn, J. Vacuum Sci. Technol. B2 (1984) 176.

[2] S.R. Kurtz, L.R. Dawson, T.E. Zipperian and S.R. Lee, Appl. Phys. Letters 52 (1988) 1581. 
[3] J.H. Kim, P.K. Bhattacharya and J. Singh, Appl. Phys. Letters 56 (1990) 1901.

[4] J.K. Abrokwah and M. Gershenzon, J. Electron. Mater. 10 (1981) 379.

[5] M.Y. Yen, R. People, K.W. Weckt and A.Y. Cho, Appl. Phys. Letters 52 (1988) 489.

[6] J.-I. Chyi, S. Kalem, N.S. Kumar, C.W. Litton and H. Morkoç, Appl. Phys. Letters 53 (1988) 1092.

[7] G.M. Williams, C.R. Whitehouse, C.F. McConville, A.G. Cullies, T. Ashiley, S.J. Courtney and C.T. Elliott, Appl. Phys. Letters 53 (1988) 1189.
[8] A. Mead and W.G. Spitzer, Phys. Rev. Letters 10 (1963) 471.

[9] A. Mead and W.G. Spitzer, Phys. Rev. A134 (1963) 713.

[10] S. Sadiq and A. Joullie, J. Appl. Phys. 6512 (1989) 15.

[11] G. Tuttle and H. Kroemer, IEEE Trans. Electron Devices ED-34 (1987) 2358.

[12] L.F. Luo, R. Beresford, W.I. Wang and H. Munekata, Appl. Phys. Letters 55 (1989) 789. 